EPiC Series in Engineering
Volume 3, 2018, Pages 2028-2032
HIC 2018. 13th International
Conference on Hydroinformatics

\title{
Finding cost-effective solutions for climate change adaptation in Bergen using extensive climate, economic and spatial data
}

\author{
Clemens Strehl ${ }^{1}$, Erle Kristvik ${ }^{2}$ and Juliane Koti ${ }^{1}$ \\ ${ }^{1}$ IWW Water Centre, Moritzstr. 26, 45476 Mülheim an der Ruhr, Germany \\ c.strehl@iww-online.de, j.koti@iww-online.de \\ ${ }^{2}$ Department of Civil and Environmental Engineering, NTNU, 7491-Trondheim, Norway \\ erle.kristvik@ntnu.no
}

\begin{abstract}
The adaptation of urban water systems to climate change is a complex management challenge. Especially urban drainage systems and their adaptation to growing climate change dynamics, like increasing variations in terms of intensity and frequency of heavy rainfall events, calls for novel adaptation approaches. Growing data availability opens the chance to find suitable cost-effective solutions to tackle climate change risks. In the Damsgård area in Bergen, combined sewer overflows discharge in the fjord during extreme rainfall events. Within the European project BINGO, an evaluation of alternative ways to reduce this environmental pressure is being conducted, using extensive climate, economic and spatial data. The analysis is going to compare different combinations of green infrastructure from the field of water sensitive urban design, like green roofs, ditches and swales. These combinations are furthermore compared with an innovative approach: using the slope of roads as emergency flood water ways.
\end{abstract}

\section{Introduction}

Within the European project BINGO (Bringing INovation to onGOing Water Management) the City of Bergen, specifically its urban drainage system in a part of the city that is vulnerable to climate change, is under study. The Damsgård area, located close to the city centre, is undergoing a substantial transition from industrial to residential purposes as a reregulated area. The area is located in the shadow of the city mountain Løvstakken and is characterized by its steep hills. Stormwater is managed by a combined system. In the past, heavy rainfall events have led to combined sewer overflows (CSO) discharging to the subjacent fjord during heavy rainfall events a number of times. According to recent studies of local climate changes in Bergen the intensity and frequency of heavy rainfall events is expected to increase [1,2], putting even more strain on the existing drainage system. Finding optimal 
solutions to reduce CSO activation both for current and future climate is needed in order to reduce the environmental pressure.

Adaptation of urban drainage in light of climate change risks is a complex management challenge. A growing base of climate data, constantly evolving climate projection models at global scale but also downscaled data is available. At regional level municipalities are consolidating their data, digitalizing urban planning documents and providing a growing number of available spatial data. In addition, there is growing data available for costs and benefits of adaptation measures in urban drainage systems from other research projects $[3,4]$.

In this paper, a multidisciplinary approach, taking advantage of this kind of data and combining them in a structured process is proposed. The expected outcome is to find suitable adaptation measures by comparing the costs as well as the performance of each adaptation measure. The assemblage of data sets formulate a decision support tool for finding cost-effective solutions for CSO reduction in the Damsgård area in Bergen.

\section{Material and Methods}

\subsection{Scenario-analysis}

In order to find cost effective solutions for reducing CSO events, a scenario analysis is conducted using the ensemble of climate data specified below under section 2.3. Future rainfall intensity and frequency is uncertain due to climate change dynamics. Therefore, a scenario analysis is beneficial to visualize this uncertainty in the future development of rainfall in Bergen and consequently the expected CSO events. The performance of alternative adaptation measures is simulated in a set of scenarios, representing different potential future developments. This approach enables the decision makers to gain a better understanding of the future's uncertain rainfall pressure at one hand, but also on the expectable performance of the adaptation measures on the other hand. The scenario-analysis incorporates four different climate change scenarios, giving different rainfall data as input for the performance simulation of the sewer system and thus expected CSO events (see also table 1):

- "Stationarity" scenario (assuming no major change in rainfall patterns, using retrospective weather data for simulations)

- "Optimistic" scenario (assuming little change in rainfall patterns)

- "Realistic" scenario (assuming realistic change in rainfall patterns)

- "Pessimistic" scenario (assuming major change in rainfall patterns)

\subsection{Cost-effectiveness analysis}

Additionally to the simulation of different climate change dynamics also the performance of alternative adaptation measures and their costs is simulated. This enables to calculate a costeffectiveness ratio (CER), allowing the decision makers to compare the adaptation measures also by the relation of costs to performance. This is a valuable decision support, if different measures are all expected to reach a sufficient reduction of future CSO events. The equation (1) below illustrates the CER formally, based on Lewin and McEvan [5]:

$$
C E R_{k}=\frac{P V(c)_{k}}{E_{k}}
$$

For the Bergen case, the effectiveness $(E)$ of a specific measure $(k)$ can be defined as the expectable reduction of CSO events on a fixed time horizon. Costs $(c)$ for a measure are calculated as present value $(P V)$, also fixed on the same time horizon. According to Lewin and McEvan a CER can be interpreted 
as "the cost required to obtain a single unit of effectiveness" [5]. Since the approach followed here compares future costs as a sum to future effectiveness also in sum of e.g. reduced CSO events, the CER can be interpreted as: average future costs to reduce one CSO event.

This CER is calculated for each combination of adaptation measure and climate change simulation, as exemplified in table 1 .

\begin{tabular}{ccccc}
\hline & $\begin{array}{c}\text { Climate } \\
\text { change: } \\
\text { "Stationarity" }\end{array}$ & $\begin{array}{c}\text { Climate } \\
\text { change: } \\
\text { "Optimistic" }\end{array}$ & $\begin{array}{c}\text { Climate } \\
\text { change: } \\
\text { "Realistic" }\end{array}$ & $\begin{array}{c}\text { Climate } \\
\text { change: } \\
\text { "Pessimistic" }\end{array}$ \\
\hline $\begin{array}{c}\text { No measure } \\
\text { No. 0 }\end{array}$ & Baseline $_{0, \mathrm{~S}}$ & Baseline $_{0, \mathrm{O}}$ & Baseline $_{0, \mathrm{R}}$ & Baseline $_{0, \mathrm{P}}$ \\
$\begin{array}{c}\text { Adaptation } \\
\text { mesure No. } \mathbf{1} \\
\text { Adaptation }\end{array}$ & $\mathrm{CER}_{1, \mathrm{~S}}$ & $\mathrm{CER}_{1, \mathrm{O}}$ & $\mathrm{CER}_{1, \mathrm{R}}$ & $\mathrm{CER}_{1, \mathrm{P}}$ \\
measure No. 2 & $\mathrm{CER}_{2, \mathrm{~S}}$ & $\mathrm{CER}_{2, \mathrm{O}}$ & $\mathrm{CER}_{2, \mathrm{R}}$ & $\mathrm{CER}_{2, \mathrm{P}}$ \\
$\ldots$
\end{tabular}

Table 1: Overview of scenarios

It is planned to compare at least two adaptation measures: (1.) A combination of green infrastructure from the field of water sensitive urban design, like green roofs, ditches and swales and (2.) using the slope of roads as emergency flood water ways. Both measures would lead to a reduced pressure of storm water in the combined sewer system.

\subsection{Data sets and simulation runs}

In order to evaluate the performance (performance equals effectiveness in the concept of the CER as explained above) of the different adaptation measures, the simulation of the urban drainage system and resulting CSO events are computed at first for each of the climate change scenarios without any adaptation measure included.

This first simulations reflect the baseline results or the "business as usual" performance of the system. For modelling the stormwater system of the Damsgård area, a Storm Water Management Model (SWMM) is used [6]. The following data sets are used to carry out he analyses:

- Ensemble of climate data, including local climate projections for Bergen generated in the BINGO project (available through the DECO plug-in of the FREVA evaluation platform [7]), local climate projections obtained by statistical downscaling of GCMs to the city of Bergen $[1,8]$, and regional climate data derived by the Norwegian Centre for Climate Services (NCCS) [2],

- Municipal spatial data covering regulatory plans, area topography, land-use, buildings, sealed surfaces etc.

- Cost data of measures reducing stormwater infiltration in the combined sewer system (available from KURAS project) [3]

Secondly, the simulations are conducted for all different adaptation measures with the same set of climate change scenario input.

All simulations are performed in an existing SWMM-based hydraulic model of the network in the Damsgård area. The model is run with continuous long-duration series, allowing for frequency analysis of CSO events at points of interest within the system and thus evaluation of resulting CSO events. This long-duration series will enable to enumerate CSO events and their aligned discharge volume. By this, an analysis of frequencies of CSO events and their discharge volume is possible. This helps to evaluate the risk associated to each scenario without any adaptation whereas subsequently, the calculative probability for the occurrence of an event is the reciprocal of its return period (1/T), derived from the 
simulated long-duration series. In order to evaluate risks, consequences of extreme weather events are determined regarding their effects on the combined sewer system and resulting CSO events. By cumulating the CSO discharge volume for each scenario, the expected annual damage can be calculated. Formally this risk can be defined as following:

$$
E A D=\sum_{i=1}^{n}\left(p_{i} * C S O_{i}\right)
$$

The EAD is defined as the sum of each calculated probability $\left(p_{i}\right)$ of each event $(i)$ and the associated environmental pressure on the fjord by the $\mathrm{CSO}$ event $\left(\mathrm{CSO}_{i}\right)$, which is measured by the discharge volume. This enables to calculate the CER for each adaptation measure, since the effective performance gain of an adaptation measure becomes obvious by comparing each "business as usual" performance results (simulation with no measure included) to the respective simulation results including a specific measure. In other words, the effectiveness $(E)$ necessary as input (as shown in equation No. 1 above) is going to be the difference between the EAD with a risk reduction measure and the EAD without a risk reduction measure. Figure 1 below illustrates the complete approach.

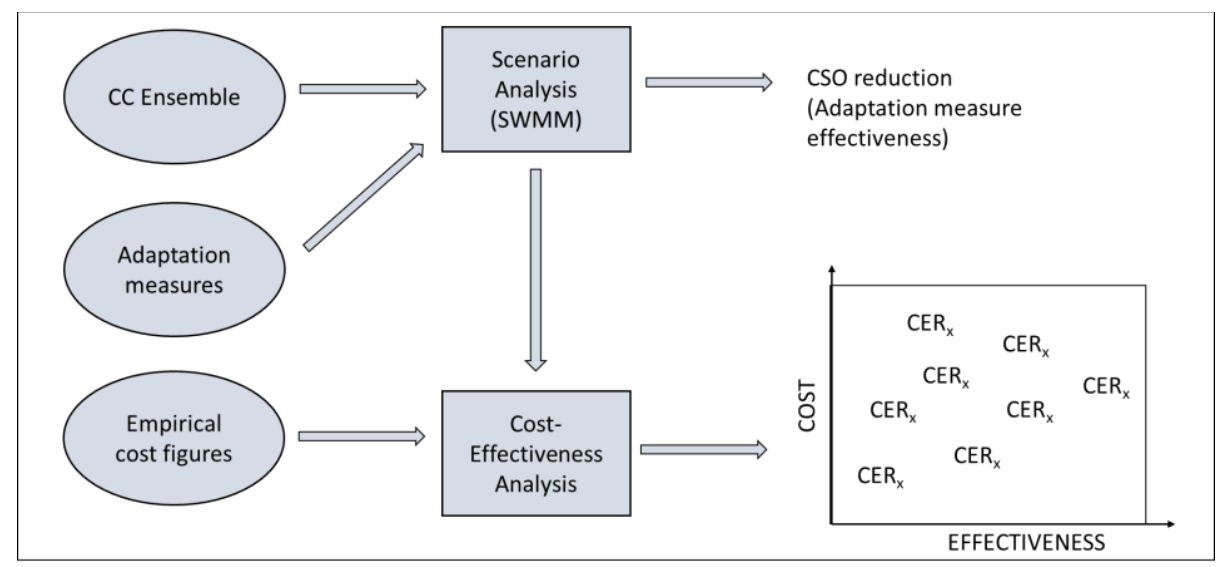

Figure 1: High-level description of methodology

\section{Results and Discussion}

The proposed method demonstrates a practical way of implementing climate data, bridging the gap between climate change researchers and practitioners. The main expected results of the study are the cost-effectiveness ratios, explaining the link between investments and expectable saved CSO amounts for the Damsgård area in Bergen. By including an ensemble of available climate projections for the city of Bergen, the decision makers are allowed to study a wide range of scenarios of the effectiveness of each measure. Further, it helps visualizing the large amount of uncertainties linked to climate change and decision making with respect to adaptation. This, ultimately, gives the decision makers a unique opportunity to find no-regret solutions for $\mathrm{CSO}$ reduction.

Finding the optimal solution requires balancing; (1) effectiveness of a measure, taking into account policies and specific goals for CSO reduction (2) costs, taking into account a specific budget, and (3) risk averseness, taking into account higher-level policies and/or information about the vulnerability of a specific area. The cost-effectiveness ratios obtained in this study are tailored to the area of Damsgård, but the rules for reaching an optimal solution are adjustable. This brings flexibility to the tool, as the 
Finding Cost-Effective Solutions for Climate Change Adaptation in Bergen Using ... C. Strehl et al.

methodology for developing the cost-effectiveness ratio could easily be adopted to other locations with different input variables but following the same methodology as outlined in this paper.

\section{Conclusion and further work}

This paper proposes a method for using extensive data sets of climate projections, spatial information and empirical cost figures to formulate a decision support tool for climate change adaptation of urban drainage systems. The data sets are used to develop cost-effectiveness ratios linking investment and operational costs of different adaptation measures to the expected effectiveness of each one. A wide range of climate scenarios are included in the cost-effectiveness ratio calculations to provide practitioners, such as municipalities, city planners and water managers, with a practical tool for taking into account the uncertainties of climate change in decision making.

\section{Acknowledgement}

The BINGO project has received funding from the European Union's Horizon 2020 Research and Innovation programme, under the Grant Agreement number 641739.

\section{References}

[1] Kristvik, E. and Muthanna, T.M. (2017): Seasonal variations in climate and the performance of stormwater collection systems. $14^{\text {th }}$ IWA/IAHR International Conference on Urban Drainage September 12 $2^{\text {th }}$ 2017, Prague, Czech Republic.

[2] Hanssen-Bauer, I., Førland, E. J., Haddeland, I., Hisdal, H., Mayer, S, Nesje, A., Nilsen, J. E. Ø., Sandven, S., Sand $\varnothing$, A. B., Sorteberg, A. \& Ådlandsvik, B. (2015): Klima i Norge 2100 (The Climate in Norway 2100), Report NCCS no 2/2015, Miljødirektoratet (Norwegian Environment Agency), Norway.

[3] Strehl, C., Offermann, M., Hein, A., Matzinger, A. (2017): Economic analysis of urban drainage scenarios in Berlin, $14^{\text {th }}$ IWA/IAHR International Conference on Urban Drainage, September $12^{\text {th }}$ 2017, Prague, Czech Republic.

[4] Matzinger, A., Schmidt, M., Strehl, C., Nickel, D., Pallasch, M., Kaiser, D., Möller, C., Lessmann, D., von Tils, R. Säumel, I., Winkler, A., Heinzmann, B., Reichmann, B., Rehfeld-Klein, M., Rouault, P. (2017): Integrated planning of urban stormwater management - Introduction to the KURAS-approach from Berlin, Germany, $14^{\text {th }}$ IWA/IAHR International Conference on Urban Drainage, September 12 ${ }^{\text {th }}$ 2017, Prague, Czech Republic.

[5] Levin, H. M. and McEwan, P. J. (2001): Cost-Effectiveness Analysis - Methods and Applications, $2^{\text {nd }}$ ed., Sage Publications, USA, UK, India, 308pp.

[6] Rossman, L. (2015): Storm Water Management Model Reference Manual Volume I - Hydrology, EPA/600/R-15/162 www2.epa.gov/water-research.

[7] Richling, A., Fischer, M., Rust, H.W., Kadow, C., Vagenas, C. and Ulbrich, U. (2016): DECOExtracting and converting meteorological driving data for hydrological models via a web-based platform. In EGU General Assembly Conference Abstracts, Vol. 18, p. 14723.

[8] Kleiven, G. H., Kristvik, E., Muthanna, T. M., Lohne, J. (2017): Local Climate Projections And Their Implications For Raingardens In Bergen. Poster presented at the Embrace the water (ETW) conference, Gothenborg, Sweden, 2017. 